\title{
Angiogenic Factors Are Increased in Circulating Granulocytes and CD34+ Cells of Myeloproliferative Neoplasms
}

\author{
Tijana Subotički ${ }^{1}$, Olivera Mitrović Ajtić ${ }^{1}$, Bojana B. Beleslin-Čokić ${ }^{2}$, Ronny Nienhold ${ }^{3}$, \\ Miloš Diklić ${ }^{1}$, Dragoslava Djikić ${ }^{1}$, Danijela Leković ${ }^{4}$, Tanja Bulat ${ }^{5}$, Dragana Marković ${ }^{1}$, \\ Mirjana Gotić ${ }^{4,6}$, Constance T. Noguchi ${ }^{7}$, Alan N. Schechter ${ }^{7}$, Radek C. Skoda ${ }^{3}$, Vladan P. \\ Čokić1, ${ }^{*}$
}

${ }^{1}$ Institute for Medical Research, University of Belgrade, Belgrade, Serbia ${ }^{2}$ Clinic for Endocrinology, Diabetes and Metabolic Diseases, Genetic Laboratory, Clinical Center of Serbia, Belgrade, Serbia ${ }^{3}$ Department of Biomedicine, Experimental Hematology, University Hospital Basel, Basel, Switzerland ${ }^{4}$ Clinic of Hematology, Clinical Center of Serbia, Belgrade, Serbia ${ }^{5}$ Institute for Nuclear Sciences "Vinča", University of Belgrade, Belgrade, Serbia ${ }^{6}$ Faculty of Medicine, University of Belgrade, Belgrade, Serbia ${ }^{7}$ Molecular Medicine Branch, National Institute of Diabetes and Digestive and Kidney Diseases, National Institutes of Health, Bethesda, Maryland

\section{Abstract}

\begin{abstract}
It has been shown that angiogenesis and inflammation play an important role in development of most hematological malignancies including the myeloproliferative neoplasm (MPN). The aim of this study was to investigate and correlate the levels of key angiogenic molecules such as hypoxiainducible factor-1a (HIF-1a), vascular endothelial growth factor (VEGF) and endothelial nitric oxide synthase (eNOS) in peripheral blood and bone marrow cells of MPN patients, along with $J A K 2 \mathrm{~V} 617 \mathrm{~F}$ mutation allele burden and effects of therapy. HIF-la and VEGF gene expression were decreased, while eNOS mRNA levels were increased in granulocytes of MPN patients. Furthermore, positively correlated and increased VEGF and eNOS protein levels were in negative correlation with HIF-a levels in granulocytes of MPN patients. According to immunoblotting, the generally augmented angiogenic factors demonstrated $J A K 2 \mathrm{~V} 617 \mathrm{~F}$ allele burden dependence only in granulocytes of PMF. The angiogenic factors were largely reduced after hydroxyurea therapy in granulocytes of MPN patients. Levels of eNOS protein expression were stimulated by Calreticulin mutations in granulocytes of essential thrombocythemia. Immunocytochemical analyses of CD34 ${ }^{+}$ cells showed a more pronounced enhancement of angiogenic factors than in granulocytes. Increased gene expression linked to the proinflammatory TGF $\beta$ and MAPK signaling pathways were detected in $\mathrm{CD}_{3} 4^{+}$cells of MPN patients. In conclusion, the angiogenesis is increased in several cell types of MPN patients supported by the transcriptional activation of inflammationrelated target genes, and is not limited to bone marrow stroma cells. It also appears that some of the benefit of hydroxyurea therapy of the MPN is mediated by effects on angiogenic factors.
\end{abstract}

\footnotetext{
*Correspondence to: Laboratory of Experimental Hematology, Institute for Medical Research, University of Belgrade, Dr. Subotica 4, Belgrade 11129, Serbia.

Conflicts of interest: None.
} 


\section{Keywords}

angiogenesis; myeloproliferative neoplasm; HIF-a; VEGF; eNOS

\section{INTRODUCTION}

Angiogenesis is a process of generation of new capillaries, and increased levels of angiogenic factors reflect the aggressiveness of tumor cells [1]. Many inducers of angiogenesis have been identified but one of the best characterized is vascular endothelial growth factor (VEGF) [2]. One of the most potent stimuli for increased VEGF production by tumor cells, in vitro and in vivo, is hypoxia via the hypoxia-inducible factor-1 alpha (HIF-1a) [3]. Recent studies have correlated HIF-1a with VEGF gene expression in cancers and myeloma cells [4,5]. The role of nitric oxide (NO) in angiogenesis is controversial since several studies have revealed that NO may induce VEGF production via the phosphoinositide-3-kinase (PI3K)/AKT/HIF-1a pathway [6], while others reported that NO might act as an inhibitor of HIF-1a [7]. These contradictory data indicate that NO effects may depend on the redox state of the cellular environment and cell type specific response [8]. Low concentrations of NO produced in response to VEGF stimulated angiogenesis, while higher concentrations associated with inflammation can inhibit angiogenesis [9].

Myeloproliferative neoplasms (MPNs) include three major entities: polycythemia vera (PV), essential thrombocythemia (ET), and primary myelofibrosis (PMF). They are clonal disorders arising in a pluripotent hematopoietic stem cell, causing an unregulated increase of terminally differentiated blood cells, with an increased risk of thrombosis and late transformation to acute myeloid leukemia [10]. Common feature of these diseases is acquired somatic mutation V617F in the $J A K 2$ gene, present in $97 \%$ of patients with PV and half of the patients with ET and PMF [11]. Increased microvessel density and VEGF expression associated with MPNs was further enhanced with high $J A K 2 V 61 \mathrm{~F}$ mutant allele burden [12]. Nevertheless, the levels of VEGF in ET patients on hydroxyurea therapy were significantly lower than in untreated ET patients [13].

The human cell surface molecule CD34 is expressed on hematopoietic and vascular endothelial progenitor cells, while capillaries of most tissues are $\mathrm{CD}^{4} 4^{+}$[14]. These bone marrow derived CD $34^{+}$cells are found circulating in peripheral blood and their efficacy in proangiogenic therapies has been studied [15]. In contrast to the typical cobblestone morphology of endothelial cells, CD3+ endothelial cells are more elongated and lack tight junctions. These $\mathrm{CD} 34^{+}$endothelial cells have the prominent impact during in vivo angiogenesis [16].

In hematological malignancies, bone marrow and lymphatic organs harbor the malignant clone that gives rise to disease, followed with imbalance of the cells, cytokines and growth factors maintaining physiological angiogenesis [17]. During the last decade, angiogenesis was shown to play an important role in the development of most hematological malignancies [18]. The aim of the present study was to investigate and correlate the levels of key angiogenic molecules HIF-1a, VEGF, and endothelial NO synthase (eNOS) in bone 
marrow, $\mathrm{CD} 34^{+}$cells and granulocytes of MPNs, according to $J A K 2 V 61 \mathrm{~F}$ and Calreticulin $(C A L R)$ mutation status and therapy.

\section{MATERIALS AND METHODS}

\section{Patients and Controls}

This study includes 160 patients and 15 healthy controls. Patients were diagnosed with MPN according to the World Health Organization classification. All patients had signed the consent form approved by the institutional review board. The median age of patients, comprising 70 males and 90 females, was $48.5 \mathrm{yr}$ (range: 27-90 yr) at the time of diagnosis, while the median age of healthy donors, comprising 10 males and 5 females, was 49 years (range: $30-70$ yr). From 160 patients included in our study, 72 were classified as PV, 47 as ET, and 41 as PMF. Of $72 \mathrm{PV}$ patients, 28 were homozygotes while 44 heterozygous for $J A K 2 V 617 \mathrm{~F}$ mutation. From 47 ET patients, 22 were without $J A K 2$ mutation and 25 heterozygous. Finally, from 41 PMF patients, 16 were without $J A K 2$ mutation, 8 homozygotes, and 17 heterozygous.

\section{Isolation of CD34+ Cells and Granulocytes From the Peripheral Blood of MPN Patients}

All de novo patients were subject to $30 \mathrm{ml}$ of peripheral blood draw on one occasion, collected in disodium ethylenediaminetetraacetic acid (EDTA). The $\mathrm{CD} 34^{+}$cells were isolated from the collected mononuclear cells using a magnetic separation column (Super Macs II, Miltenyi Biotec, Bergisch Gladbach, Germany) and a mixture of magnetic microbeads conjugated with antibody against CD34 (Miltenyi Biotec) according to the manufacturer's instructions. The pellet formed during centrifugation with lymphocyte separation medium (LSM, PAA Laboratories GmbH, Pasching, Austria), is comprised mostly of erythrocytes and granulocytes. Erythrocytes were removed by using lysing solution $\left(0.15 \mathrm{M} \mathrm{NH}_{4} \mathrm{Cl}, 0.1 \mathrm{mM} \mathrm{Na}_{2}\right.$ EDTA, $\left.12 \mathrm{mM} \mathrm{NaHCO}_{3}\right)$. The viable CD34 ${ }^{+}$cell and granulocyte were counted by a trypan-blue exclusion technique (Life Technologies, Bleiswijk, Netherlands).

\section{DNA Sequencing}

Genomic DNA was extracted from peripheral blood granulocytes of MPN patients by using the proteinase K and phenol-chloroform technique. Single nucleotide mutation JAK2V61T was characterized by DNA sequencing after PCR amplification. PCR amplification was performed with wild-type $J A K 2$-specific forward primer 5' TGGCAGAGAGAATTTTCTGAACT-3' and reverse primer 5'TTCATTGCTTTCCTTTTTCACA-3', confirmed by electrophoresis on an ethidium bromide-impregnated $1 \%$ agarose gel. PCR amplified samples are analyzed by sequencing on an automated ABI PRISM 3130 Genetic Analyzer (Applied Biosystems Inc, Foster City, CA) with AB DNA Sequencing Analysis Software (v 5.2) by using the Big Dye Terminator v3.1 Ready Reaction Cycle Sequencing Kit.

The mutation analysis of CALR exon 9, -52bp deletion (type1) and +5bp insertion (type2), was performed by allele specific PCR as previously reported [19]. The primer sequences are 5'-3'sequence CALR-intr8-fam-fwd FAM-GGCAAGGCCCTGAGGTGT and CALR-ex9- 
rev GGCCTCAGTCCAGCCCTG. The PCR products were analyzed by fragment analysis with ABI3130xl Genetic Analyzer (Applied Biosystems Inc).

\section{Isolation of Total RNA and RT-PCR}

Total RNA from CD34+ ${ }^{+}$cells and granulocytes was isolated using TRIzol (Life

Technologies). Concentration and integrity of total RNA was assessed using Ultrospec 3300 spectrophotometer (Amersham Pharmacia, Upsala, Sweeden). Equal amounts of RNA from different samples were transcribed into cDNA using the Maxima First Strand cDNA Synthesis kit (Thermo Fisher Scientific, Waltham, MA).

\section{Real-Time Quantitative PCR}

Quantitative real-time PCR analyses of human VEGF gene was performed using a LightCycler 480 (Roche Diagnostics, Roche Applied Science, Mannheim, Germany) and Taqman oligonucleotide probe 5' CCA AGT GGT CCC AGG CTG CAC C 3' and forward 5' TTG CTG CTC TAC CTC CAC CAT 3' and reverse 5' CAC TTC GTG ATG ATT CTG CCC 3 ' primers. The oligonucleotide probes were fluorescently labeled on the 5' end with FAM (6-carboxy fluorescein) and on the 3' end with BlackBerry Quencher (BBQ). Quantitative real-time PCR analyses of human HIF-la gene was performed using oligonucleotide probe 5' AGC AAC AGG GAA AGC GTG GCT 3' and forward 5' GGC AGG AAG ATT GTC ATG GAC 3' and reverse 5' TCT GTC TGT CAC ATG GGT GAT GAA 3' primers (TIB MOLBIOL GmbH, Berlin, Germany). Real-time quantitative PCR of eNOS gene was performed on a Mastercycler EP RealPlex (Eppendorf AG, Hamburg, Germany) using the Maxima SYBR Green/ROX qPCR master mix (Thermo Scientific, Cambridge, UK) and forward: 5' CGG CAT CAC CAG GAA GAA GA 3' and reverse 5' GCC ATC ACC GTG CCC AT 3' primers. $\beta$-actin was used as an internal control for normalization of the examined angiogenic factors. Real-time PCR was performed in granulocytes of total 83 MPN patients, but because of overlapping (samples from the same patient): HIF-la was evaluated in 50 samples (20 PV, 15 ET, 15 PMF, plus 6 controls), VEGF in 52 samples (20 PV, $16 \mathrm{ET}, 16 \mathrm{PMF}$, plus 6 controls) and eNOS in 58 samples (20 PV, 23 ET, 15 PMF, plus 6 controls). Real-time PCR was performed in $\mathrm{CD} 4^{+}$cells of total 57 MPN patients, but because of overlapping: HIF-la was evaluated in 36 samples (16 PV, 11 ET, 9 PMF, plus 5 controls), VEGF in 44 samples (22 PV, 11 ET, 11 PMF, plus 5 controls), and eNOS in 39 samples (15 PV, 15 ET, 9 PMF, plus 5 controls).

\section{Western Blot}

Granulocytes were lysed in chilled radioimmuno precipitation assay (RIPA) lysis buffer (50 $\mathrm{mM}$ Tris-HCl pH 7.6, $150 \mathrm{mM}$ sodium chloride, $1 \%$ Triton $\mathrm{x}-100,1 \%$ sodium deoxycholate, $0.1 \%$ sodium dodecyl sulphate, $2 \mathrm{mM}$ EDTA and $50 \mathrm{mM}$ sodium fluoride) at a ratio of $1 \mathrm{ml}$ of buffer on $1 \times 10^{8}$ cells. A protease inhibitor cocktail (Pierce, Thermo Fisher Scientific, Waltham, MA) and sodium orthovanadate were added to the lysis buffer just prior to use. Lysates were incubated at $4^{\circ} \mathrm{C}$ for $25 \mathrm{~m}$ and then centrifuged at $10000 \mathrm{~g}, 4^{\circ} \mathrm{C}$, for $15 \mathrm{~min}$. Protein concentration was determined by the bicinchoninic acid (BCA) Protein Assay Kit (Pierce, Thermo Fisher Scientific, Waltham, MA) and samples were stored at $-70^{\circ} \mathrm{C}$. In order to examine activated HIF-1a protein, we conducted separation of the nuclear and cytoplasmic fractions of granulocytes using NE-PER Kit (Pierce, Thermo Fisher Scientific). 
For Western blotting, equal amounts of protein samples were run on polyacrylamide gels and transferred to polyvinylidene difluoride membrane. The membrane was blocked with $5 \%$ bovine serum albumin (BSA, Applichem, $\mathrm{GmbH}$, Darmstadt, Germany) for $1 \mathrm{~h}$ at room temperature (RT) and probed with primary antibodies to HIF-1a (R\&D Systems, Abingdon, UK), a-tubulin (Sigma-Aldrich, Dorset, UK), VEGF, eNOS, and H2B (Santa Cruz Biotechnologies, Dallas, TX). Peroxidase conjugated goat anti-rabbit imunoglobulin (Santa Cruz Biotechnologies) and goat anti-mouse imunoglobulin (Pierce, Thermo Fisher Scientific), were used as secondary antibodies. Hyperfilm was developed to visualize the secondary antibody by the enhanced chemiluminescence reagent system (GE Healthcare, Amersham, UK) according to the manufacturer's instructions. The content of HIF-1a, VEGF, and eNOS in cells extracts was estimated by the densitometry of scanned immunoblot band using the Image Master Total Lab (GE Healthcare) software. Western blotting was performed in granulocytes of total 60 MPN patients, but because of overlapping: HIF-1a was evaluated in 42 samples (12 PV, 12 ET, 18 PMF, plus 4 controls), VEGF in 49 samples (17 PV, 17 ET, 15 PMF, plus 4 controls), and eNOS in 40 samples (11 PV, 12 ET, 17 PMF, plus 4 controls).

\section{Immunocytochemistry/Immunohistochemistry}

For cytoplasmatic staining, granulocytes were collected onto microscope glass slides by cytospins $\left(2 \times 10^{4}\right.$ cells/each) and fixed by acetone at room temperature (RT). Bone marrow biopsy specimens were fixed in $10 \%$ neutral formalin solution for $24-36 \mathrm{~h}$, then decalcified in EDTA buffer for $3 \mathrm{~h}$ and embedded in paraffin. The tissue sections were cut at $5 \mu \mathrm{m}$, heated at $56^{\circ} \mathrm{C}$ for $60 \mathrm{~min}$, then deparaffinized and rehydrated through a series of xylenes and alcohols followed by an epitope retrieval step. Samples were treated with $3 \% \mathrm{H}_{2} \mathrm{O}_{2}$ solution in phosphate buffered saline (PBS) to block endogenous peroxidase activity. The next step was incubation with anti-HIF-1a antibody (Abcam) anti-VEGF antibody (BD Pharmingen, Cambridge, UK) and anti-eNOS antibody (Santa Cruz Biotechnology) in a humidity chamber over night at RT. Immunostaining was performed using the streptavidinbiotin technique ( $\mathrm{LSAB}^{+} / \mathrm{HRP}$ Kit, DAKO). Immunoreactivity was visualized with DAKO Liquid $\mathrm{DAB}^{+}$Substrate/Chromogen System counterstained with Mayer's hematoxylin (Merck, Whitehouse Station, NJ). For the negative control samples, normal serum and trisbuffered saline (TBS) buffer (1:500) were pipetted without primary antibodies.

Immunoreactive cells were analysed and scored at five powered fields in each sample using a computer-supported imaging system (Analysis Pro 3.1) connected to the light microscope (Olympus AX70, Hamburg, Germany) with an objective magnification of $\times 40$. Immunocytochemical staining for all three angiogenic factors was evaluated in granulocytes of 36 cases (11 PV, $10 \mathrm{ET}, 15 \mathrm{PMF}$, plus 4 controls). Immunohistochemical staining was performed in granulocytes of total 61 MPN patients, but because of overlapping: HIF-1a was evaluated in 36 cases (11 PV, $10 \mathrm{ET}, 15 \mathrm{PMF}$, plus 4 controls), VEGF in 40 cases (15 PV, 10 ET, 15 PMF, plus 5 controls), and eNOS in 36 cases (10 PV, 11 ET, 15 PMF, plus 5 controls).

\section{Microarray Analysis}

The human oligo probe set was purchased from Operon Human Genome Array-Ready Oligo Set Version 4.0 (Eurofins MWG Operon, Huntsville, AL) which contained 35035 
oligonucleotide probes, representing approximately 25100 unique genes. Total human universal RNA (HuURNA, BD Biosciences, Palo Alto, CA) served as a universal reference control in the competitive hybridization. In microarray studies, for determination of gene expression in $\mathrm{CD}_{3} 4^{+}$cells we used: eight biological replicates of healthy donors, seven biological replicates of PV patients, nine biological replicates of ET patients, and four biological replicates of PMF patients. We amplified total RNA from $\mathrm{CD} 34^{+}$cells using the Amino Allyl MessageAmp ${ }^{\mathrm{TM}}$ II amplified RNA (aRNA) Amplification kit (Life Technologies Corp., Carlsbad, CA), according to the manufacturer's instructions using 300 ng of total RNA for amplification. The prepared hybridization mixture of cDNA probe and aRNA was added on the array in slide and placed in MAUI hybridization chamber (BioMicro Systems, Inc., Salt Lake City, UT) and incubated overnight at $42^{\circ} \mathrm{C}$. Data Filtration, normalization, and analysis were performed as already described [20]. The microarray data are available from Gene Expression Omnibus (http://www.ncbi.nlm.nih.gov/ geo; accession no. GSE55976).

\section{Statistical Analysis}

The one way ANOVA and Dunnett's posttest were applied using Prism 4 software (GraphPad Software Inc., San Diego, CA). The Pearson's correlation tests were applied where appropriate. The results are expressed as the mean \pm SEM, and differences at $P<0.05$ are accepted as the level of significance.

\section{RESULTS}

\section{Angiogenic Factors Gene Expression in Granulocytes and CD34+ of MPN Patients}

Using DNA sequencing of 160 MPN patients, JAK2V61T mutation was detected in all PV patients and 53\% of ET and 61\% of PMF patients. CALR mutations type 1 and 2 were detected in $69 \%$ of ET and $83 \%$ of PMF patients negative for JAK2V61T mutation. We found that granulocytes of PV patients had significantly reduced $H I F-l a$ gene expression in comparison to controls $(P<0.05)$, as well as PMF patients without $J A K 2 V 617$ mutation (Figure 1A). In CD34+ cells of MPNs and granulocytes of ET patients, the HIF-la expression did not significantly change compared to controls (not shown). In granulocytes of MPN patients, VEGF demonstrated decreased expression in ET and PMF patients without $J A K 2 V 61 \mathrm{~T}$ and PV homozygous for JAK2V617F mutation (Figure 1B). In CD34 ${ }^{+}$cells, expression of $V E G F$ was significantly decreased in PV and ET patients $(P<0.05$, not shown). eNOS mRNA levels were generally significantly increased in granulocytes of MPN patients (Figure 1C), as well as in CD34+ cells of PMF (P < 0.01, not shown). HIF-la and VEGF gene expression, independently of $J A K 2$ status, did not change significantly in granulocytes of MPNs, in contrast to eNOS.

\section{Angiogenic Factor Levels in Circulating Granulocytes and CD34+ Cells of MPN Patients}

Angiogenic factors, at protein level, were significantly increased in ET and PV independently of $J A K 2$ status (Figure 2A). Our immunoblotting analyses of total HIF-1a protein expression revealed a significant increase in granulocytes of MPN patients, demonstrating dependence of $J A K 2 V 61$ F mutant allele burden only in PMF (Figure 2B). The activated HIF-1a was significantly increased only in nuclear fraction of PV 
granulocytes (1.73 fold, not shown). Also, VEGF protein levels were increased in PV and ET patients, but only significantly increased in JAK2V61T homozygous PMF patients (Figure 2C). However, among the PV homozygous JAK2V617F patients, there is a negative correlation between VEGF and HIF-1a protein levels $(r-0.969, P<0.001$, Table 1$)$. Examination of the eNOS protein levels in granulocytes showed a significant increase of this protein in MPN patients (Figure 2D). In addition, among ET patients without $J A K 2 V 61 \mathrm{~T}$ mutation, there is a negative correlation between eNOS and HIF-1a protein levels ( $r-$ $0.939, P<0.05)$. The increased angiogenic factors were almost generally and significantly increased in $J A K 2 V 61$ F positive patients with PMF.

While immunocytochemical analyses of $\mathrm{CD} 34^{+}$cells showed a significant increase of angiogenic factors in MPN patients independent of JAK2 mutation (Figure 3A), a negative correlation between HIF-1 $a$ and VEGF was noted in CD34 ${ }^{+}$cells among ET patients $(r-$ $0.797, P<0.05)$. Similarly, but less prominent, the percentage of HIF-1a, VEGF-, and eNOS-positive cells was significantly increased in granulocytes of MPN patients, except for VEGF in PMF (Figure 3B). Increased quantity of angiogenic factor positive cells in granulocytes of MPNs was not influenced by JAK2V61TF mutant allele burden (Figure 4AC). In addition, between VEGF and eNOS there is a significant positive correlation in PV (JAK2V61T heterozygous $r=0.536, \mathrm{P}<0.05$, homozygous $r=0.723, P<0.001$ ) and PMF patients (JAK2V61 T absent $r=0.726, P<0.001$, heterozygous $r=0.709, P<0.001$, homozygous $r=0.859, P<0.001)$ as well as in JAK2V617F heterozygous ET $(r=0.406, P$ $<0.05$, Table 1). While number of HIF-1a-positive cells was increased overall in the MPN patients relative to control, except for PMF patients homozygous for JAK2V61T (Figure 4A), a negative correlation was noted between HIF-1a and VEGF among JAK2V61TF heterozygous PMF patients $(r-0.513, P<0.05)$. Interestingly, the immunocytochemical analysis of granulocytes of MPN patients showed significant and uniform decrease in percentage of the angiogenic factors positive cells after therapy with hydroxyurea (Figure $5 \mathrm{~A}-\mathrm{C})$. This decrease in percentage of positive cells was particularly striking in PV patients for the angiogenic factors (especially HIF-1a), regarding their increased levels in comparison to ET and PMF patients.

\section{Angiogenic Factors Levels in Bone Marrow of MPN Patients}

The percentage of HIF-1a positive cells in the cytoplasm of bone marrow stroma cells showed a significant increase in $J A K 2 V 61 T$ F heterozygous PV (Figure 6A). A significant increase of HIF-1a positive cells was also observed in bone marrow of PMF patients without $J A K 2 V 617 \mathrm{~F}$ mutation (Figure 6A), with decreased levels in the nucleus of MPN bone marrow stroma cells (not shown). A significant increase in percentage of VEGF positive cells was observed in bone marrow of JAK2V61T heterozygous PV and ET patients (Figure 6B). In bone marrow of PMF patients it was evident an increased percentage of eNOS, significant in $J A K 2 V 61$ F heterozygous PMF patients (Figure 6C). A significant reduction in percentage of eNOS was apparent in $J A K 2 V 61 \mathrm{~F}$ negative ET patients (Figure 6C). In addition, there is a significant positive correlation between eNOS and VEGF positive cells in bone marrow of PMF patients without $J A K 2 V 61$ F mutation $(r=0.703, P<0.05$, Table 1). According to presented results, the $J A K 2 V 61 \pi \mathrm{F}$ mutant allele burden did not demonstrate steady influence to angiogenic factors in bone marrow stroma of MPN patients. 
VEGF, eNOS, and HIF-1a were expressed by the same bone marrow populations: megakaryocytes, macrophages, and myeloid precursors that revealed a moderate to strong immunostaining intensity in MPNs.

\section{Angiogenesis Related Signaling Pathways in CD34+ Cells of MPN}

Using microarray analysis we presented activation of angiogenesis related signaling pathways and genes in $\mathrm{CD} 34^{+}$cells of MPNs (Figure 7). We can see that components of protein kinase $\mathrm{C}(\mathrm{PKC})$, transforming growth factor-beta (TGF $\beta$ ) and mitogen-activated protein kinase (MAPK) signaling pathways were largely activated, while less prominent in PI3K/AKT signaling pathway. So, the $\mathrm{CD} 34^{+}$cell proliferation, actin rearrangement and migration were stimulated, whereas a cell survival was less affected in MPNs. MAPK1, $P L C G 2$, and TGFBR1 gene expression was absent in controls, but increased in MPN CD34 ${ }^{+}$ cells (Table 2). Also, SMAD2 and PIK3R1 gene expression was sporadically present in healthy controls and increased in MPN CD $34^{+}$cells. The statistically significant increase was observed for $R A C 1$ (in PMF) and $R A C 2$ (in $\mathrm{PV}$ ) genes, while reduction for $K R A S$ and $R A C 3$ genes (in ET) in comparison to controls. In CD34 ${ }^{+}$cells of ET, presence of $J A K 2 V 61$ F mutation augmented PXN and reduced $R A C 3$ ( $\mathrm{P}<0.05$, not shown) gene expression. In PV patients homozygous for $J A K 2 V 61 T \mathrm{~F}$ mutation, $H I F-1 \mathrm{a}$ gene expression was further reduced and $A K T 2$ was increased $(P<0.05)$, although $R A C 2$ and $P X N$ genes had increased expression in $\mathrm{PV}$ patients heterozygous for $J A K 2 V 617 \mathrm{~F}(\mathrm{P}<0.01$, not shown).

\section{Angiogenic Factor Levels According to Calreticulin Mutation in MPN Patients}

To examine does $C A L R$ status impact the gene and protein expression of angiogenic factors in ET and PMF, we performed parallel studies in accordance to $C A L R$ mutations. It has been observed that $H I F-l a$ and $V E G F$ mRNA expression has been significantly reduced in granulocytes of ET and PMF, not influenced by CALR mutations (Figure 8A). In contrast, eNOS mRNA levels were significantly increased in ET regardless of CALR status, but more prominent in the absence of $C A L R$ mutation (Figure 8A). On the protein level, angiogenic factors were generally increased in granulocytes of ET demonstrating significance, except VEGF in $C A L R$ mutation negative patients (Figure 8B). Only eNOS demonstrated $C A L R$ mutation dependence, significantly increased $(\mathrm{P}<0.05)$ in ET patients with $C A L R$ mutation. In PMF patients, only HIF-1a protein has been increased with $C A L R$ wild type (Figure 8B). Besides HIF-1 $a$ and VEGF positive cells, increased eNOS positive granulocytes demonstrated significance in $C A L R$ mutation positive versus negative ET patients (Figure 8C). HIF-1a positive granulocytes were also increased in PMF, regardless of $C A L R$ status, while VEGF positive cells were significantly increased $(\mathrm{P}<0.05)$ in $C A L R$ mutation negative versus positive PMF patients (Figure $8 \mathrm{C}$ ). The eNOS positive granulocytes were significantly increased in PMF with $C A L R$ mutation (Figure 8C). It has been observed significantly decreased VEGF and eNOS levels $(\mathrm{P}<0.05)$ in $\mathrm{CD} 34^{+}$cells of ET patients with $C A L R$ mutation (not shown). Imunohistochemical analysis of bone marrow stroma cells of ET and PMF patients revealed that angiogenic factors were not influenced by $C A L R$ status (not shown). 


\section{DISCUSSION}

We analyzed levels of key angiogenic molecules HIF-1a, VEGF, and eNOS in peripheral blood and bone marrow of MPNs and determined their correlation with JAK2V61TF mutational status and therapy. We found commonly decreased HIF-la and VEGF gene expression in granulocytes while eNOS mRNA levels were generally increased in granulocytes of MPNs. Analyses of angiogenic proteins expression showed their significant increase in granulocytes of MPN patients. Immunocytochemical analyses of granulocytes and $\mathrm{CD} 34^{+}$cells confirmed that the percentages of HIF-1a, VEGF, and eNOS positive cells were generally increased, with positive correlation between VEGF and eNOS. Immunohistochemical analyses of bone marrow revealed increased percentage of HIF-1a positive cells in the cytoplasm of PV patients and decreased in the nucleus of MPN patients, while the percentages of VEGF and eNOS positive cells were increased in JAK2 mutation positive ET and PMF patients, respectively. The eNOS protein expression demonstrated CALR dependence in granulocytes of ET patients, stimulated by the presence of CALR mutation.

Patients with PV and PMF showed an increased microvessel density compared to ET or healthy controls, while VEGFR-1 protein expression correlated with microvessel density and increased VEGF expression in bone marrow of MPNs [21-23]. The bone marrow VEGF expression positively correlated with increased serum levels of VEGF in MPNs $[18,24]$. The VEGF concentration was also increased in plasma of patients with ET [25]. Our results showed that ET patients, heterozygous for $J A K 2$ mutation, had significantly increased percentage of VEGF positive cells in bone marrow. Augmented quantities of neutrophil granulocytes have been detected in the peripheral blood and tumor tissues of patients with cancers [26], as well as leukocytes and thrombocytes in MPNs [20]. Activated neutrophil granulocytes released VEGF and were directly angiogenic by stimulating macrovascular and microvascular endothelial cell proliferation and tubule formation [27]. Vice versa VEGF recruited the proangiogenic circulating subset of neutrophils that expressed large amount of matrix metalloproteinase 9 (MMP-9) that mediates angiogenesis [28]. In our study group, VEGF protein expression was generaly increased in granulocytes of MPN patients, reaching statistical significance in majority of $J A K 2 V 61 \mathrm{~T}$ defined groups. There is a positive correlation between VEGF and eNOS levels in granulocytes of MPNs. VEGF-mediated eNOS Ser1177 phosphorylation controlled angioblast and endothelial cells division, activating vasculogenesis and angiogenesis [29]. Increased microvessel density, evaluated by $\mathrm{CD} 4^{+}$cells, correlated with the absolute number of VEGF positive cells and fibrosis in MPNs [12]. According to presented results, the percentage of VEGF positive cells was also significantly increased in $\mathrm{CD} 34^{+}$cells of MPN patients. A pathological interaction between polymorphonuclear leukocytes and megakaryocytes correlated with myelofibrosis development [30].

In the absence of HIF-1a, fewer bone marrow-derived CD45 ${ }^{+}$myeloid cells are recruited to the tumors, decreasing mobilization of VEGF [31]. VEGF negatively correlated with HIF-1a in granulocytes of PV and PMF as well as in CD34+ cells of ET in our results. Further on, NO increased the VEGF gene expression by augmenting HIF-1 activity [32]. In a positive feedback, the VEGF-induced angiogenesis involved NO production from activated 
eNOS [33]. According to our results, eNOS gene and protein expressions were increased in granulocytes of MPN patients, while the percentage of eNOS and VEGF positive cells were characterised with a significant positive correlation in granulocytes and bone marrow. Activated HIF-1a protein levels were increased in nuclear fraction of granulocytes from PV and ET patients. Hydroxyurea treatment reduced erythroid progenitor and CD $34^{+}$cells growth in PV and ET [34]. The level of VEGF in patients on hydroxyurea therapy were significantly lower than in untreated ET patients [13]. Namely, in order to determine changes in HIF-1a, VEGF and eNOS positive granulocytes of patients treated with hydroxyurea, we found significantly decreased percentage of the angiogenic factors positive cells in MPN patients after hydroxyurea treatment.

AKT inhibitor suppressed colony formation from hematopoietic progenitor cells in PMF and reduced megakaryocytic burden in bone marrow [35]. PKC-epsilon transgenic mice spontaneously developed a myeloproliferative-like disease, with significant increases of neutrophils in peripheral blood and bone marrow [36]. Double inhibition of PI3K/AKT and mammalian target of rapamycin (mTOR) signaling induced cell-cycle growth arrest and apoptosis of $\mathrm{CD}^{+} 4^{+}$PMF cells [37]. It has been shown that MPN patients have increased peripheral blood and bone marrow plasma levels of both bioactive and total TGF $\beta 1$ [38]. Moreover, we already demonstrated the increased proinflammatory IL-6 levels in patients with MPN [39]. According to our microarray analysis of angiogenesis related signaling: proinflammatory PKC, TGF $\beta$, and MAPK signaling pathways demonstrated upregulation of related gene members, in contrast to limited anti-inflammatory PI3K/AKT signaling pathway.

Patients with JAK2-mutated ET had higher risk of thrombosis and transformation than those with $C A L R$-mutated ET. A significant proportion of patients with JAK2-mutated ET, but none of those with a $C A L R$ mutation, progressed to PV during their clinical course [40]. Increased NO levels and activation of eNOS were detected in human umbilical vein endothelial cells by CALR stimulation [41], in accordance with our finding that mutated $C A L R$ stimulated eNOS protein levels and positive cells in ET. The gain of-function property of mutant $C A L R$ preferentially associated with c-MPL, the TPO receptor, led to constitutive activation of AKT and activation of eNOS, demonstrating CALR interaction with angiogenic factors [42-44]. Neutrophil elastase cleaves an N-terminus CALR peptide characterized as vasostatin, while levels of serum vasostatin in acute myeloid leukemia inversely correlated with bone marrow vascularization [45]. Overexpressed CALR upregulated the expression and secretion of VEGF and correlated with high microvessel density [46].

We showed the angiogenic factors were generally increased in examined tissues of MPN patients. Angiogenic factors had more pronounced levels in granulocytes and CD $34^{+}$cells, than in bone marrow stroma cells, demonstrating the importance of inflammatory granulocytes in angiogenesis development. HIF-1a protein expression negatively correlated with eNOS and VEGF in granulocytes, while the later two angiogenic factors levels shared significant positive correlation in patients with MPNs. The numbers of VEGF, HIF-1a and eNOS immuno positive cells were significantly lower in MPN patients after therapy with hydroxyurea, and may relates to prolonged survival and better quality of life. 


\section{ACKNOWLEDGMENTS}

We thank Raj Puri at the Division of Cellular and Gene Therapies, Center for Biologics Evaluation and Research, FDA, Bethesda, MD, USA for his support in microarray analysis. This research was supported by grant from the Serbian Ministry of Education, Science and Technological Development [No. OI175053], by SCOPES bilateral project of the Swiss National Science Foundation (IZ73Z0_152420), and by Intramural Research Program at the National Institute of Diabetes and Digestive and Kidney Diseases, NIH, Bethesda.

\section{Abbreviations:}

AKT2

BSA

EDTA

eNOS

ET

HIF-1a

KRAS

MAPK

MMP-9

MPN

NO

PIK3R1

PKC

PMF

PV

PLCG2

PXN

RAC 1/2/3

SMAD2

TGF $\beta$

TGFBR1

VEGF v-akt murine thymoma viral oncogene homolog 2

bovine serum albumin

ethylenediaminetetraacetic acid

endothelial NO synthase

essential thrombocythemia

hypoxia-inducible factor- $1 \mathrm{a}$

kirsten rat sarcoma viral oncogene homolog

mitogen-activated protein kinase

matrix metalloproteinase 9

myeloproliferative neoplasm

nitric oxide

phosphoinositide-3-kinase regulatory subunit 1

protein kinase $\mathrm{C}$

primary myelofibrosis

polycythemia vera

1-Phosphatidylinositol-4,5-bisphosphate phosphodiesterase gamma-2

paxillin

Ras-related C3 botulinum toxin substrate 1/2/3

SMAD family member 2

transforming growth factor-beta

TGF-beta receptor type-1

vascular endothelial growth factor 


\section{REFERENCES}

1. El-Kenawi AE, El-Remessy AB. Angiogenesis inhibitors in cancer therapy: Mechanistic perspective on classification and treatment rationales. Br J Pharmacol 2013;170:712-729. [PubMed: 23962094]

2. Shibuya M Vascular endothelial growth factor and its receptor system: Physiological functions in angiogenesis and pathological roles in various diseases. J Biochem 2013;153:13-19. [PubMed: 23172303]

3. Ahn GO, Seita J, Hong BJ, et al. Transcriptional activation of hypoxia-inducible factor-1 (HIF-1) in myeloid cells promotes angiogenesis through VEGF and S100A8. Proc Natl Acad Sci USA 2014;111:2698-2703. [PubMed: 24497508]

4. Inglis DJ, Lavranos TC, Beaumont DM, et al. The vascular disrupting agent BNC105 potentiates the efficacy of VEGF and mTOR inhibitors in renal and breast cancer. Cancer Biol Ther 2014;15:15521560. [PubMed: 25482941]

5. Storti P, Bolzoni M, Donofrio G, et al. Hypoxia-inducible factor (HIF)-1a suppression in myeloma cells blocks tumoral growth in vivo inhibiting angiogenesis and bone destruction. Leukemia 2013;27:1697-1706. [PubMed: 23344526]

6. Lee BL, Kim WH, Jung J, et al. A hypoxia-independent upregulation of hypoxia-inducible factor-1 by AKT contributes to angiogenesis in human gastric cancer. Carcinogenesis 2008;29:44-51. [PubMed: 17984117]

7. Cattaneo MG, Cappellini E, Benfante R, et al. Chronic deficiency of nitric oxide affects hypoxia inducible factor-1a (HIF-1a) stability and migration in human endothelial cells. PLoS ONE 2011;6:e29680. [PubMed: 22216344]

8. Grimm EA, Sikora AG, Ekmekcioglu S. Molecular pathways: Inflammation-associated nitric-oxide production as a cancer supporting redox mechanism and a potential therapeutic target. Clin Cancer Res 2013;19:5557-5563. [PubMed: 23868870]

9. Roberts DD, Isenberg JS, Ridnour LA, Wink DA. Nitric oxide and its gatekeeper thrombospondin-1 in tumor angiogenesis. Clin Cancer Res 2007;13:795-798. [PubMed: 17289869]

10. Kralovics R, Passamonti F, Buser AS, et al. A gain-of-function mutation of JAK2 in myeloproliferative disorders. N Engl J Med 2005;352:1779-1790. [PubMed: 15858187]

11. Baxter EJ, Scott LM, Campbell PJ, et al. Cancer Genome Project. Acquired mutation of the tyrosine kinase JAK2 in human myeloproliferative disorders. Lancet 2005;365: 1054-1061. [PubMed: 15781101]

12. Medinger M, Skoda R, Gratwohl A, et al. Angiogenesis and vascular endothelial growth factor-/ receptor expression in myeloproliferative neoplasms: Correlation with clinical parameters and JAK2-V617F mutational status. Br J Haematol 2009;146:150-157. [PubMed: 19466975]

13. Treliński J, Wierzbowska A, Krawczyńska A, et al. Plasma levels of angiogenic factors and circulating endothelial cells in essential thrombocythemia: Correlation with cytoreductive therapy and JAK2-V617F mutational status. Leuk Lymphoma 2010;51:1727-1733. [PubMed: 20615083]

14. Sidney LE, Branch MJ, Dunphy SE, Dua HS, Hopkinson A. Concise review: Evidence for CD34 as a common marker for diverse progenitors. Stem Cells 2014;32:1380-1389. [PubMed: 24497003]

15. Hristov M, Weber C. Endothelial progenitor cells in vascular repair and remodeling. Pharmacol Res 2008;58:148-151. [PubMed: 18722530]

16. Siemerink MJ, Klaassen I, Vogels IM, Griffioen AW, Van Noorden CJ, Schlingemann RO. CD34 marks angiogenic tip cells in human vascular endothelial cell cultures. Angiogenesis 2012;15:151163. [PubMed: 22249946]

17. Medinger M, Mross K. Clinical trials with anti-angiogenic agents in hematological malignancies. J Angiogenes Res 2010;2:10. [PubMed: 20569499]

18. Alonci A, Allegra A, Bellomo G, et al. Evaluation of circulating endothelial cells, VEGF and VEGFR2 serum levels in patients with chronic myeloproliferative diseases. Hematol Oncol 2008;26:235-239. [PubMed: 18504767]

19. Klampfl T, Gisslinger H, Harutyunyan AS, et al. Somatic mutations of calreticulin in myeloproliferative neoplasms. N Engl J Med 2013;369:2379-2390. [PubMed: 24325356] 
20. Čokić VP, Mossuz P, Han J, et al. Microarray and proteomic analyses of myeloproliferative neoplasms with a highlight on the mTOR signaling pathway. PLoS ONE 2015; 10:e0135463. [PubMed: 26275051]

21. Wrobel T, Mazur G, Surowiak P, Wolowiec D, Jelen M, Kuliczkowsky K. Increased expression of vascular endothelial growth factor (VEGF) in bone marrow of patients with myeloproliferative disorders (MPD). Pathol Oncol Res 2003;9:170-173. [PubMed: 14530810]

22. Boiocchi L, Vener C, Savi F, et al. Increased expression of vascular endothelial growth factor receptor 1 correlates with VEGF and microvessel density in Philadelphia chromosome negative myeloproliferative neoplasms. J Clin Pathol 2011;64: 226-231. [PubMed: 21217153]

23. Steurer M, Zoller H, Augustin F, et al. Increased angiogenesis in chronic idiopathic myelofibrosis: Vascular endothelial growth factor as a prominent angiogenic factor. Hum Pathol 2007;38:10571064. [PubMed: 17442379]

24. Panteli K, Bai M, Hatzimichael E, Zagorianakou N, Agnantis NJ, Bourantas K. Serum levels, and bone marrow immunohistochemical expression of, vascular endothelial growth factor in patients with chronic myeloproliferative diseases. Hematology 2007;12:481-486. [PubMed: 17852434]

25. Musolino C, Calabro L, Bellomo G, et al. Soluble angiogenic factors: Implications for chronic myeloproliferative disorders. Am J Hematol 2002;69:159-163. [PubMed: 11891801]

26. Dumitru CA, Lang S, Brandau S. Modulation of neutrophil granulocytes in the tumor microenvironment: Mechanisms and consequences for tumor progression. Semin Cancer Biol 2013;23:141-148. [PubMed: 23485549]

27. McCourt M, Wang JH, Sookhai S, Redmond HP. Proinflammatory mediators stimulate neutrophildirected angiogenesis. Arch Surg 1999;134:1325-1331. [PubMed: 10593330]

28. Christoffersson G, Vågesjö E, Vandooren J, et al. VEGF-A recruits a proangiogenic MMP-9delivering neutrophil subset that induces angiogenesis in transplanted hypoxic tissue. Blood 2012;120:4653-4662. [PubMed: 22966168]

29. Gentile C, Muise-Helmericks RC, Drake CJ. VEGF-mediated phosphorylation of eNOS regulates angioblast and embryonic endothelial cell proliferation. Dev Biol 2013;373: 163-175. [PubMed: 23103584]

30. Schmitt A, Drouin A, Massé JM, Guichard J, Shagraoui H, Cramer EM. Polymorphonuclear neutrophil and megakaryocyte mutual involvement in myelofibrosis pathogenesis. Leuk Lymphoma 2002;43:719-724. [PubMed: 12153156]

31. Du R, Lu KV, Petritsch C, et al. HIF1alpha induces the recruitment of bone marrow-derived vascular modulatory cells to regulate tumor angiogenesis and invasion. Cancer Cell 2008;13:206220. [PubMed: 18328425]

32. H1 Kimura, Weisz A, Kurashima Y, et al. Hypoxia response element of the human vascular endothelial growth factor gene mediates transcriptional regulation by nitric oxide: Control of hypoxia-inducible factor-1 activity by nitric oxide. Blood 2000;95:189-197. [PubMed: 10607702]

33. J1 Kroll, Waltenberger J. VEGF-A induces expression of eNOS and iNOS in endothelial cells via VEGF receptor-2 (KDR). Biochem Biophys Res Commun 1998;252:743-746. [PubMed: 9837777]

34. Andreasson B, Swolin B, Kutti J. Hydroxyurea treatment reduces haematopoietic progenitor growth and CD34 positive cells in polycythaemia vera and essential thrombocythaemia. Eur J Haematol 2000;64:188-193. [PubMed: 10997885]

35. Khan I, Huang Z, Wen Q, et al. AKT is a therapeutic target in myeloproliferative neoplasms. Leukemia 2013;27: 1882-1890. [PubMed: 23748344]

36. Wheeler DL, Reddig PJ, Ness KJ, Leith CP, Oberley TD, Verma AK. Overexpression of protein kinase $\mathrm{C}$-\{epsilon $\}$ in the mouse epidermis leads to a spontaneous myeloproliferative-like disease. Am J Pathol 2005;166:117-126. [PubMed: 15632005]

37. Fiskus W, Verstovsek S, Manshouri T, et al. Dual PI3K/AKT/mTOR inhibitor BEZ235 synergistically enhances the activity of JAK2 inhibitor against cultured and primary human myeloproliferative neoplasm cells. Mol Cancer Ther 2013;12: 577-588. [PubMed: 23445613]

38. Campanelli R, Rosti V, Villani L, et al. Evaluation of the bioactive and total transforming growth factor $\beta 1$ levels in primary myelofibrosis. Cytokine 2011;53:100-106. [PubMed: 20801055] 
39. Čokić VP, Mitrović-Ajtić O, Beleslin-Čokić BB, et al. Proinflammatory cytokine IL-6 and JAKSTAT signaling pathway in myeloproliferative neoplasms. Mediators Inflamm. 2015; 2015:453020. [PubMed: 26491227]

40. Rumi E, Pietra D, Ferretti V, et al. JAK2 or CALR mutation status defines subtypes of essential thrombocythemia with substantially different clinical course and outcomes. Blood. 2014;123:1544-1551. [PubMed: 24366362]

41. Ding H, Hong C, Wang Y, et al. Calreticulin promotes angiogenesis via activating nitric oxide signalling pathway in rheumatoid arthritis. Clin Exp Immunol. 2014;178:236-244. [PubMed: 24988887]

42. Araki M, Yang Y, Masubuchi N, et al. Activation of the thrombopoietin receptor by mutant calreticulin in CALR mutant myeloproliferative neoplasms. Blood. 2016;127: 1307-1316. [PubMed: 26817954]

43. Han L, Schubert C, Köhler J, et al. Calreticulin-mutant proteins induce megakaryocytic signaling to transform hematopoietic cells and undergo accelerated degradation and Golgi-mediated secretion. J Hematol Oncol. 2016; 9:45. [PubMed: 27177927]

44. Cokic VP, Beleslin-Cokic BB, Tomic M, Stojilkovic SS, Noguchi CT, Schechter AN. Hydroxyurea induces the eNOS-cGMP pathway in endothelial cells. Blood 2006;108:184-191. [PubMed: 16527893]

45. Mans S, Banz Y, Mueller BU, Pabst T. The angiogenesis inhibitor vasostatin is regulated by neutrophil elastase dependent cleavage of calreticulin in AML patients. Blood 2012;120:2690 2699. [PubMed: 22915645]

46. Chen $\mathrm{CN}$, Chang CC, Su TE, et al. Identification of calreticulin as a prognosis marker and angiogenic regulator in human gastric cancer. Ann Surg Oncol 2009;16:524-533. [PubMed: 19050968] 


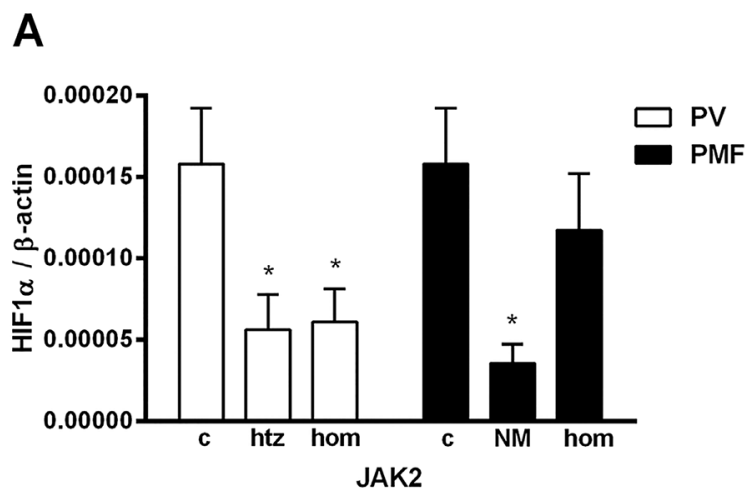

B

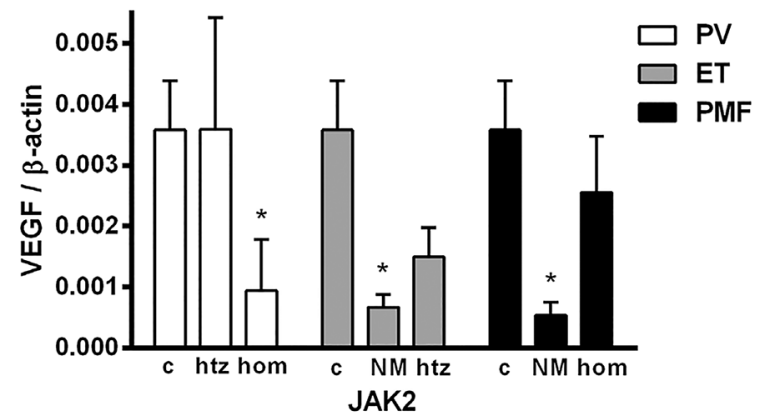

C

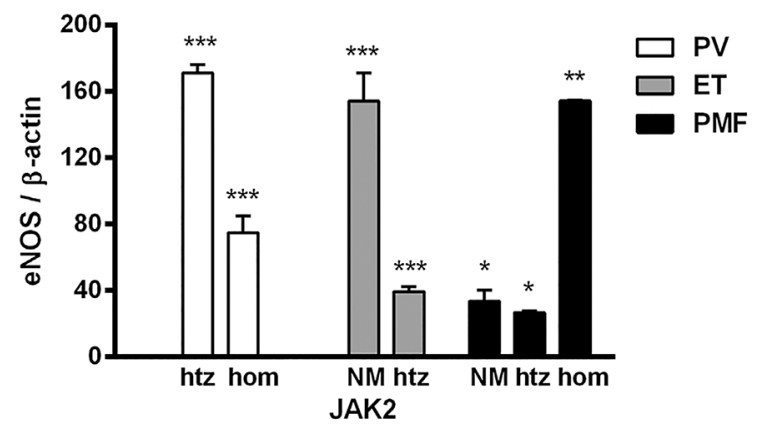

Figure 1.

mRNA expression of HIF-1a, VEGF, and eNOS gene in granulocytes of MPN patients. (A) HIF-la gene expression was significantly reduced in PV heterozygous (htz), homozygous (hom), and PMF without $J A K 2 \mathrm{~V} 617 \mathrm{~F}$ mutation (NM) patients, while (B) VEGF gene expression was reduced in PV homo, ET, and PMF NM patients compared to controls (c). (C) Increased eNOS gene expression in MPN patients is presented as direct ratio with controls using SYBR Green. Values are mean SEM $(n=5-10$ patients per individual JAK2 mutant allele burden: hom, htz, and NM). $* P<0.05, * * P<0.01$, and $* * * P<0.001$. 
A

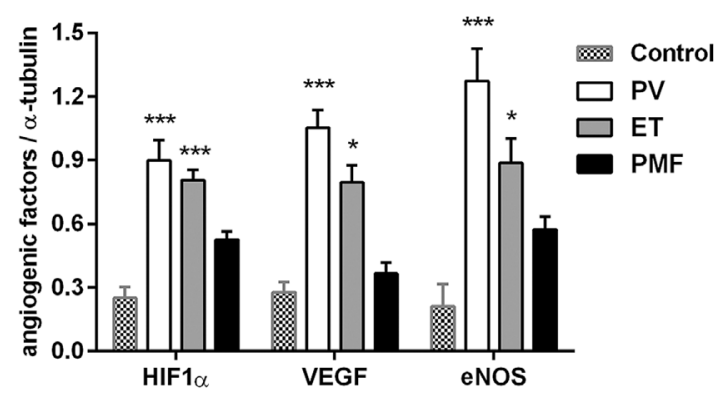

C

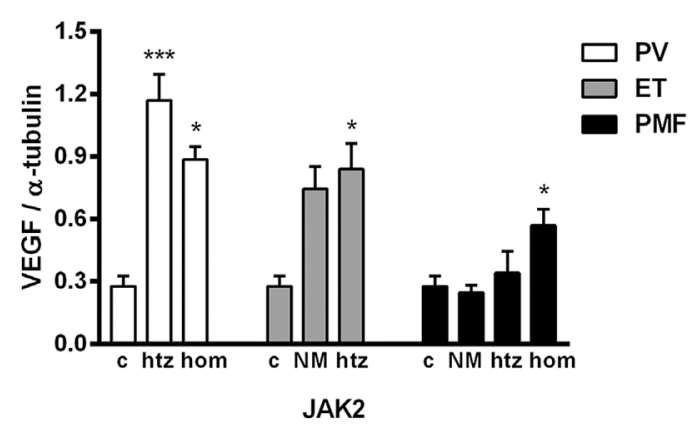

B

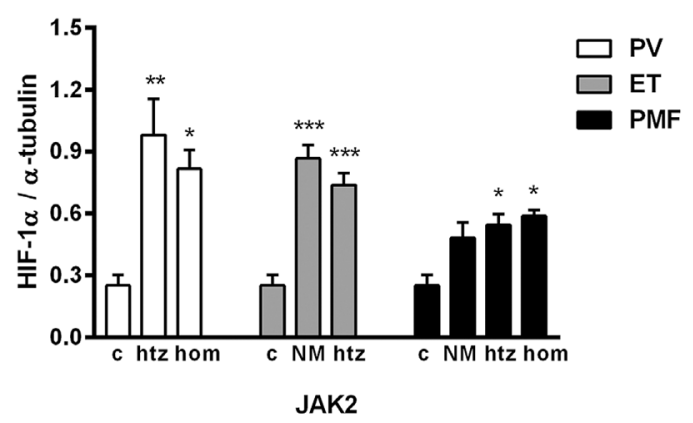

D

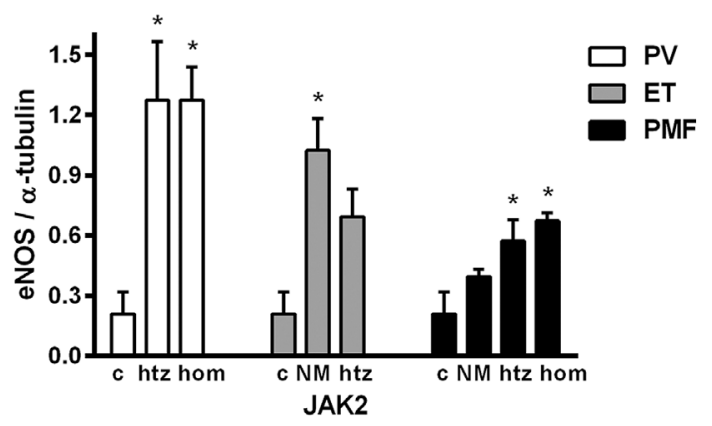

Figure 2.

Expression of HIF-1a, VEGF, and eNOS proteins in granulocytes of MPN patients determined by immunoblotting. Densitometry revealed increased protein expression of (A) angiogenic factors in MPNs; (B) total HIF-1a in MPN patients heterozygous (htz), homozygous (hom), and no JAK2V617F mutation (NM, $n=6$ patients per individual JAK2 mutant allele burden); (C) VEGF in htz, hom, and NM ( $n=5-9)$; (D) eNOS proteins in htz, hom, and NM ( $n=5-7)$ of MPN patients compared to controls (c, $n=4)$. Values are mean \pm SEM. $* P<0.05, * * P<0.01$, and $* * * P<0.001$. 


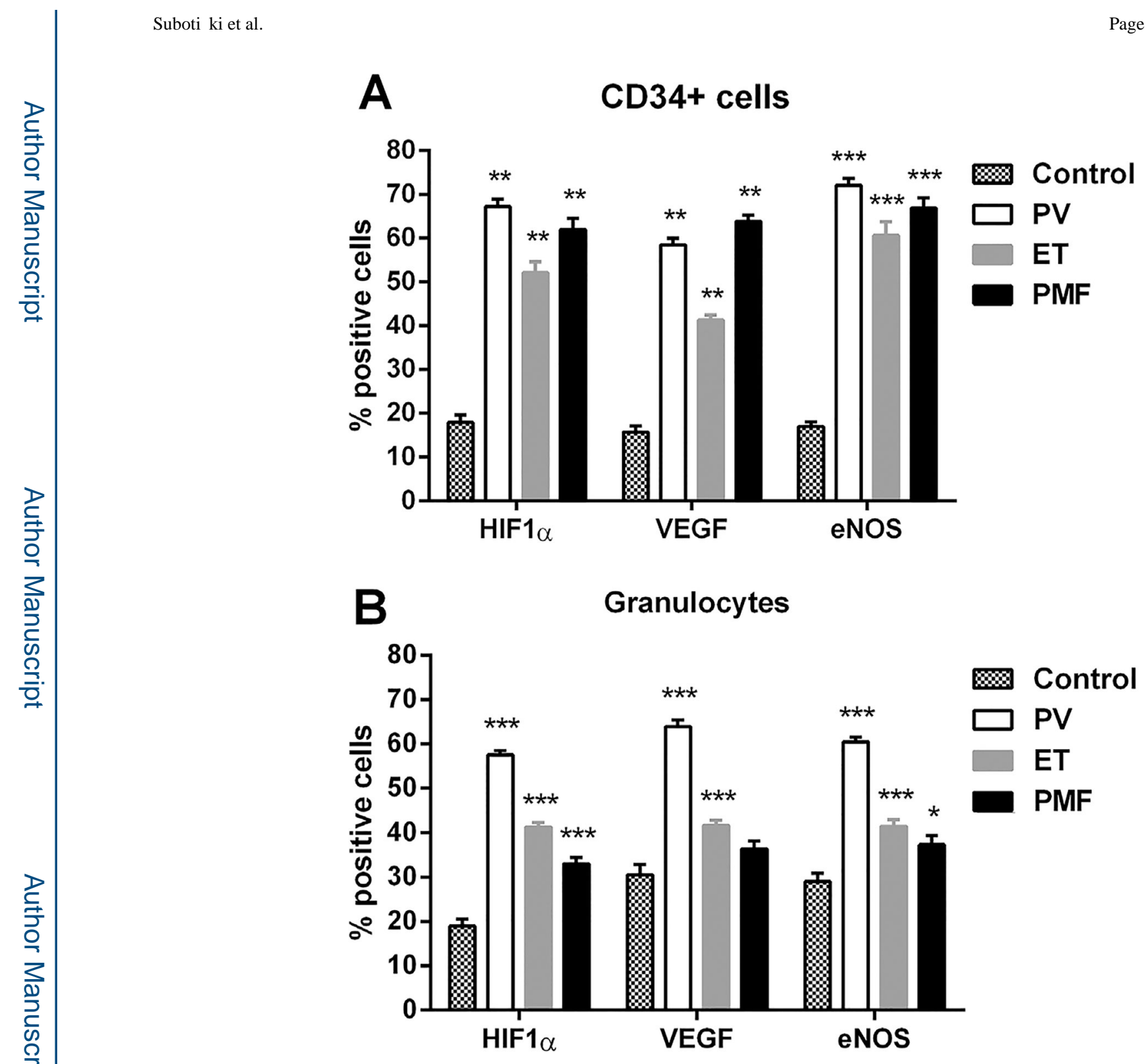

Figure 3.

Immunocytochemical analysis of angiogenic factors positive cells in $\mathrm{CD} 34^{+}$cells and granulocytes of MPN patients. The percentage of angiogenic factors showed a significant increase in (A) $\mathrm{CD}_{4} 4^{+}$cells ( $n=5$ per individual MPN) and (B) granulocytes of ET, PV, and PMF patients $(n=10-15)$. Values are mean \pm SEM. $* P<0.05, * * P<0.01$, and $* * * P<$ 0.001 . 


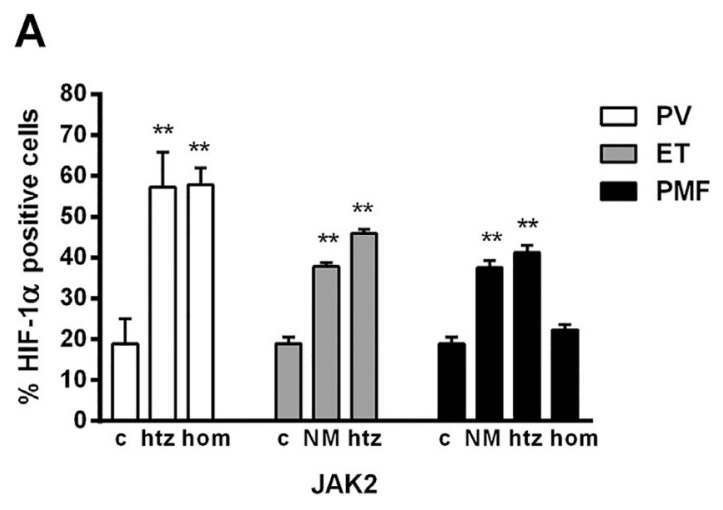

B

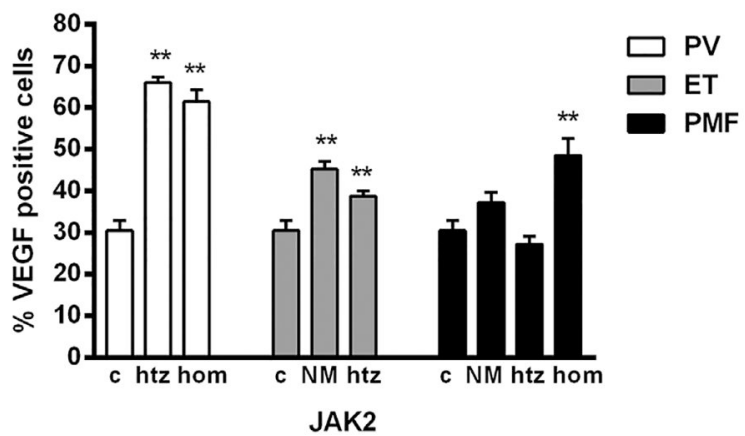

C

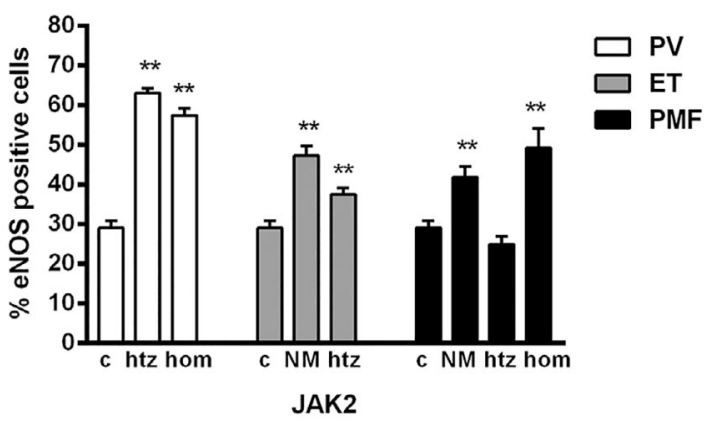

Figure 4.

Immunocytochemical analysis of angiogenic factors positive cells in granulocytes of MPN patients according to $J A K 2 \mathrm{~V} 617 \mathrm{~F}$ mutant allele burden. Quantitative analysis of (A) HIF-1a, (B) VEGF, and (C) eNOS percentage of positive cells in granulocytes revealed its significant increase in MPN patients heterozygous (htz), homozygous (hom), or no $J A K 2 \mathrm{~V} 617 \mathrm{~F}$ mutation (NM) versus controls (c), $n=5-6$ patients per individual JAK2 mutant allele burden and controls. Values are mean \pm SEM. $* * P<0.01$. 
A

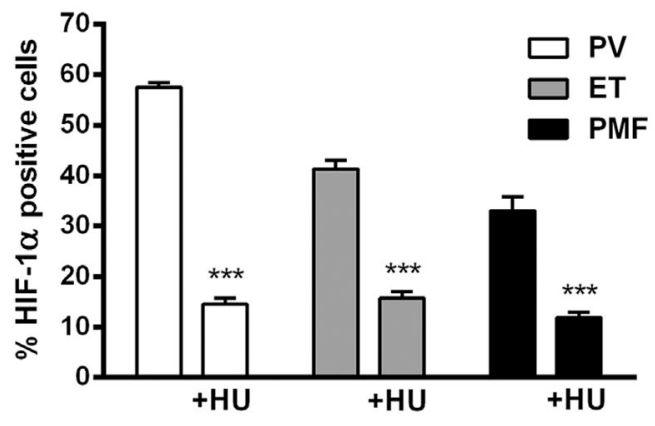

B

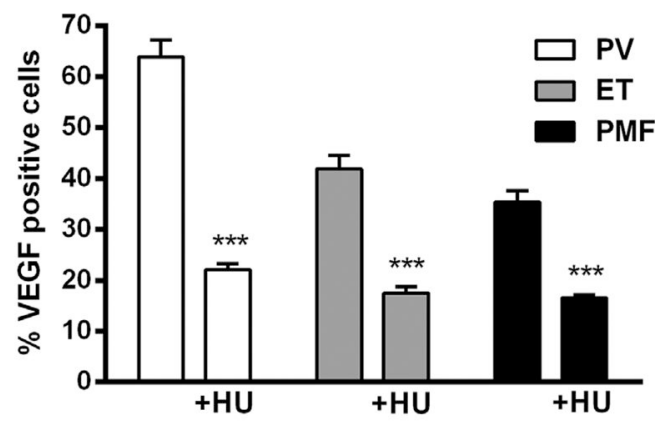

C

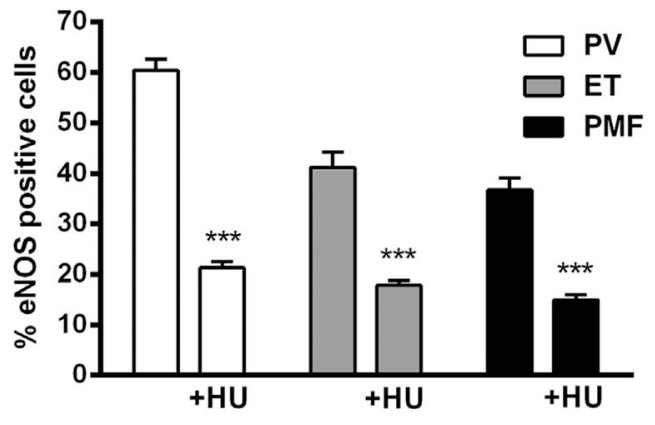

Figure 5.

Immunocytochemical analysis of angiogenic factors positive cells in granulocytes of MPN patients after at least 6 months therapy with hydroxyurea (HU). A significant decrease in percentage of (A) HIF-1a, (B) VEGF, and (C) eNOS positive cells in ET, PV, and PMF ( $n=$ $3 \times 6$ patients before and after therapy with $\mathrm{HU})$. Values are mean \pm SEM. $* * * P<0.001$. 

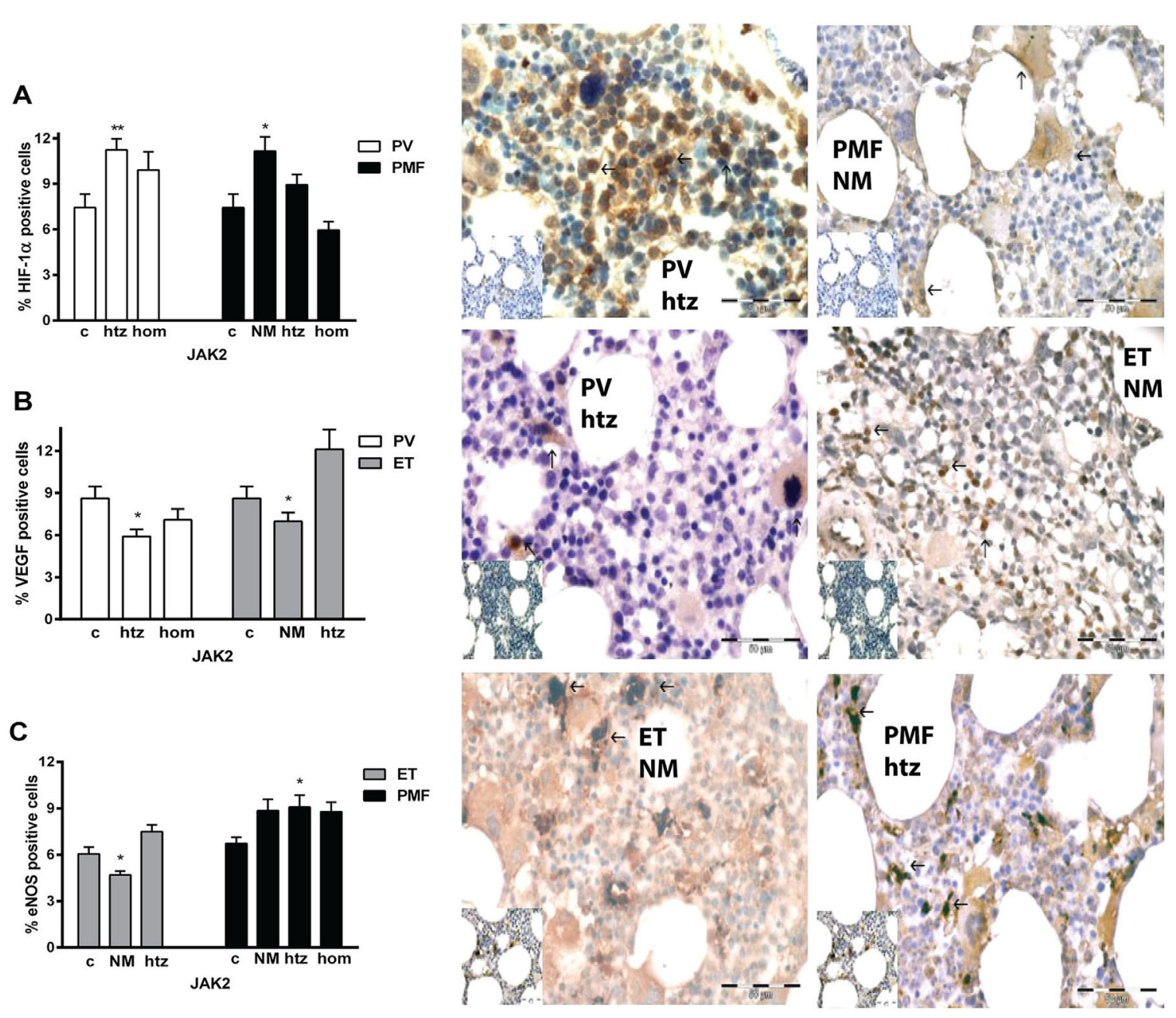

Figure 6.

Immunohistochemical analysis of angiogenic factors positive cells in the bone marrow of MPN patients. (A) Increased percentage of cytoplasmatic HIF-1a positive cells is apparent in PV htz and PMF no JAK2V617F mutation (NM) patients presented in adjacent immunohistochemical graphs. (B) It has been detected a significant increase in percentage of VEGF positive cells in ET htz and decrease in PV htz patients, while (C) eNOS positive cells are increased in PMF htz patients and reduced in ET NM patients versus controls (c). Arrows indicate positive brown cells. Corresponding controls are at the bottom left corner of immunohistochemical graphs. Bar $50 \mu \mathrm{m}$. Values are mean \pm SEM ( $n=5-6$ patients per individual JAK2 mutant allele burden). ${ }^{*} P<0.05, * * P<0.01$. 


\section{MAPK1 $\longrightarrow$ Proliferation $\longrightarrow$ Angiogenesis}
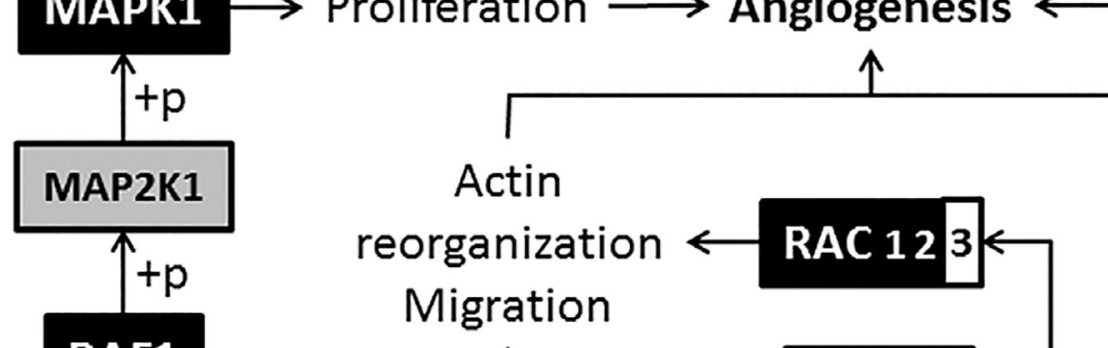

\section{RAF1}

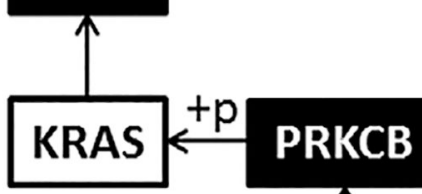

Actin reorganization

Migration

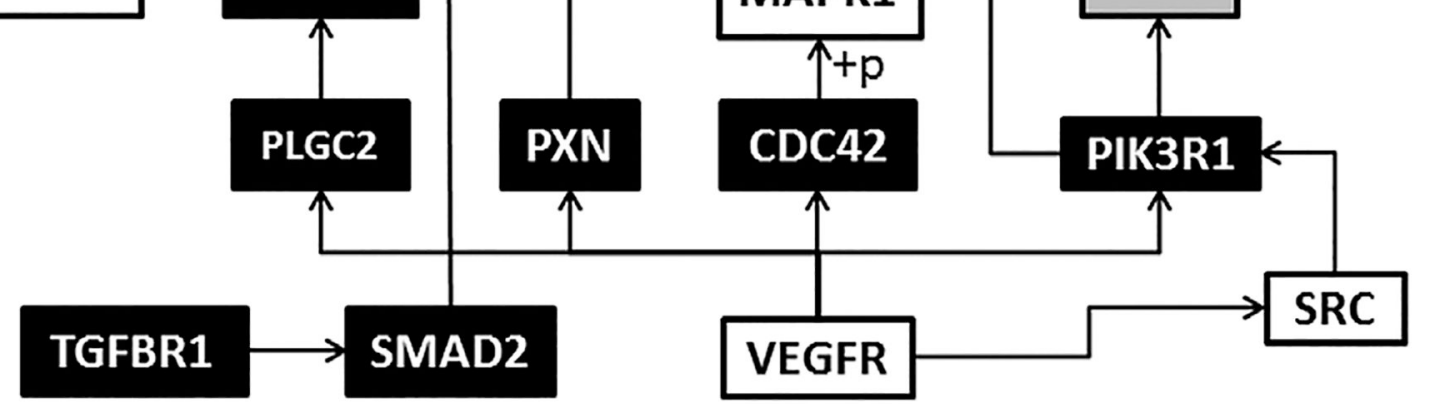

Figure 7.

Angiogenesis signaling pathway in $\mathrm{CD} 34^{+}$cells of MPN origin. (+p) phosphorylation, $\rightarrow$ stimulation; empty boxes represent downregulated, gray boxes no changed and black boxes upregulated genes versus control (corresponding to Table 2). 


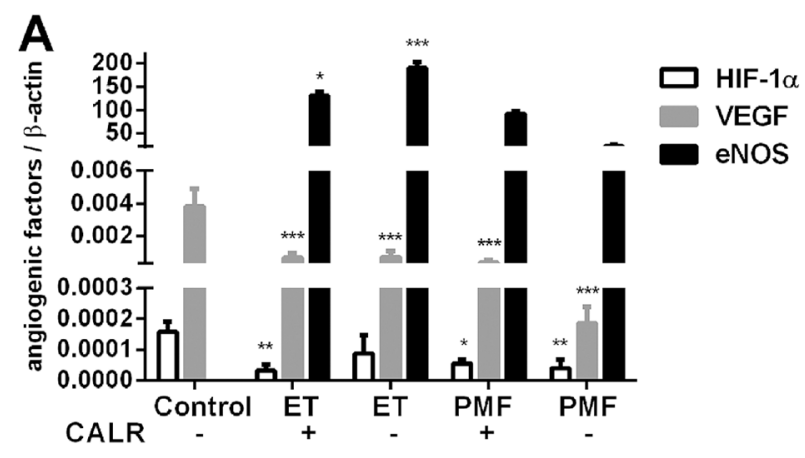

B
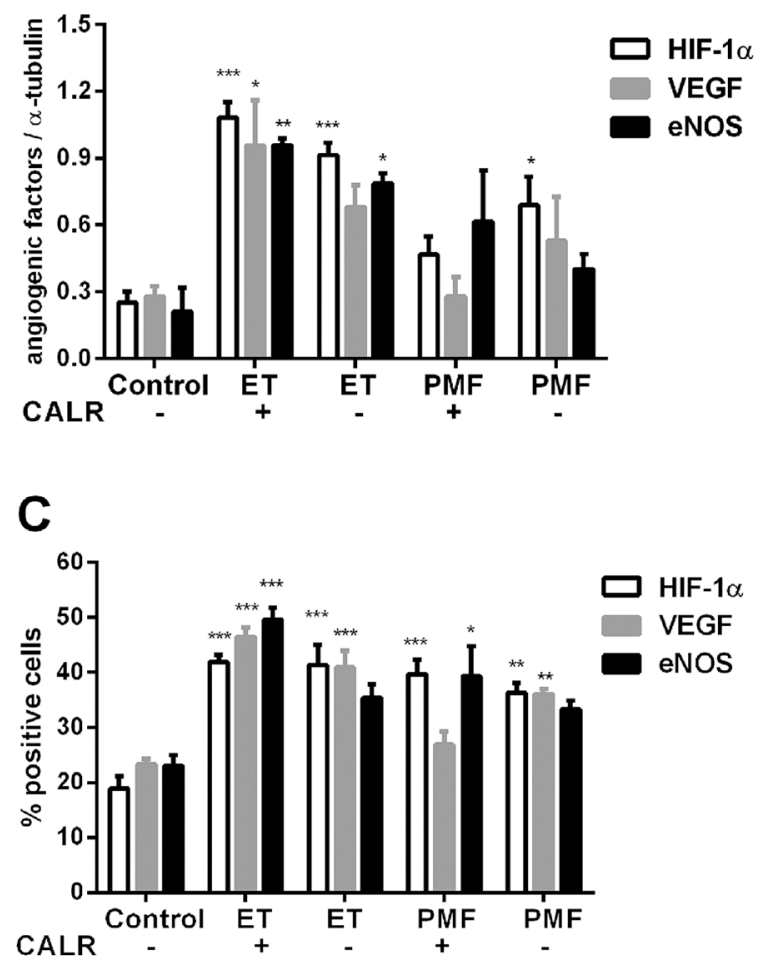

Figure 8.

Expression of angiogenic factors according to CALR status in granulocytes of MPN patients. (A) HIF-la and $V E G F$ gene expression were significantly reduced in PV and PMF, while eNOS gene expression (presented as direct ratio with controls using SYBR Green) was increased in ET. (B) Increased angiogenic factors protein expression in ET determined by Western blot. (C) Increased levels of angiogenic factors positive cells in ET and PMF determined by immunocytochemistry. Values are mean $\pm \operatorname{SEM}(n=4-5) .{ }^{*} P<0.05, * * P<$ 0.01 , and $* * * P<0.001$. 


\section{롤 \\ 文}

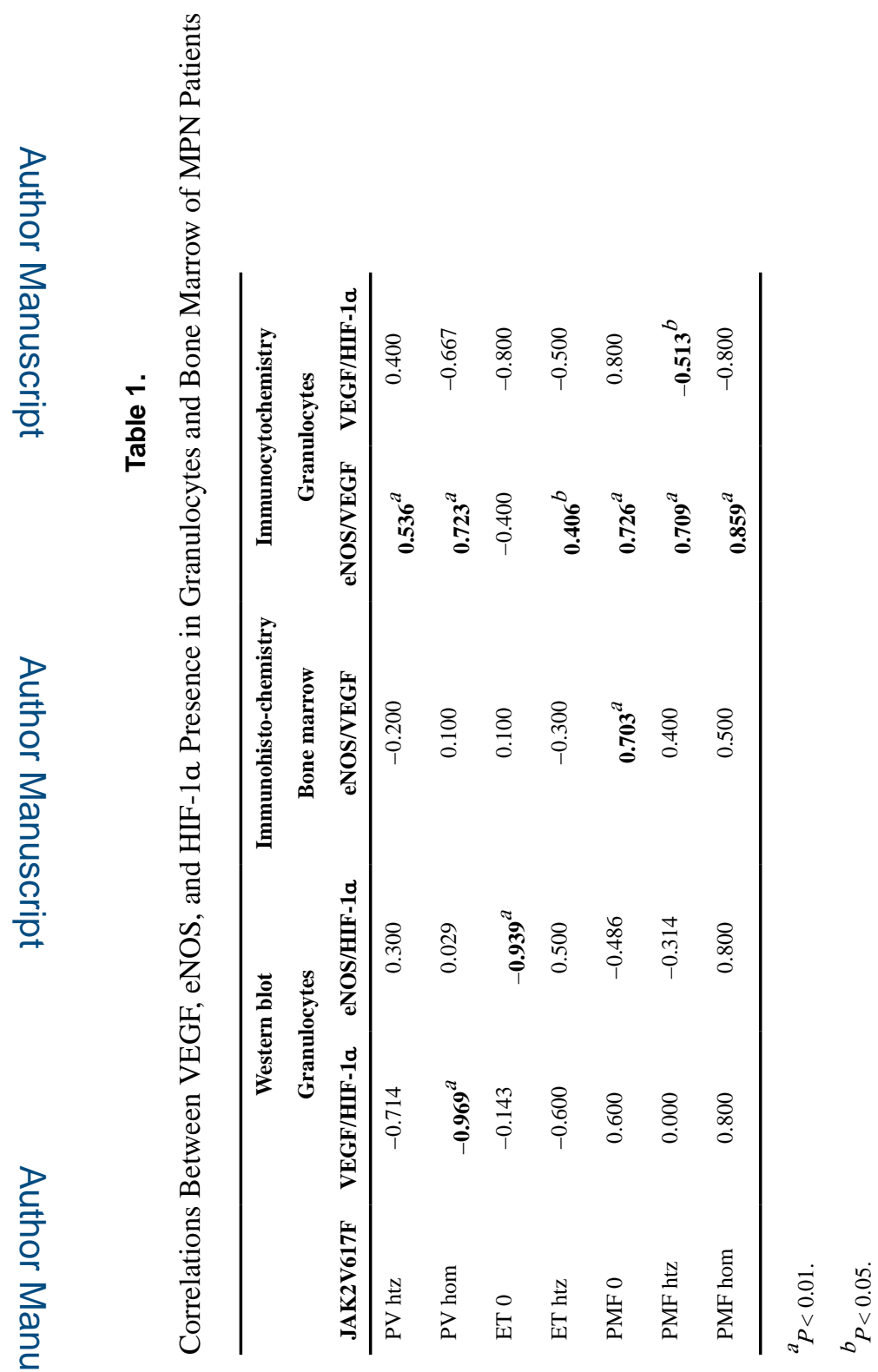

Mol Carcinog. Author manuscript; available in PMC 2020 June 10. 


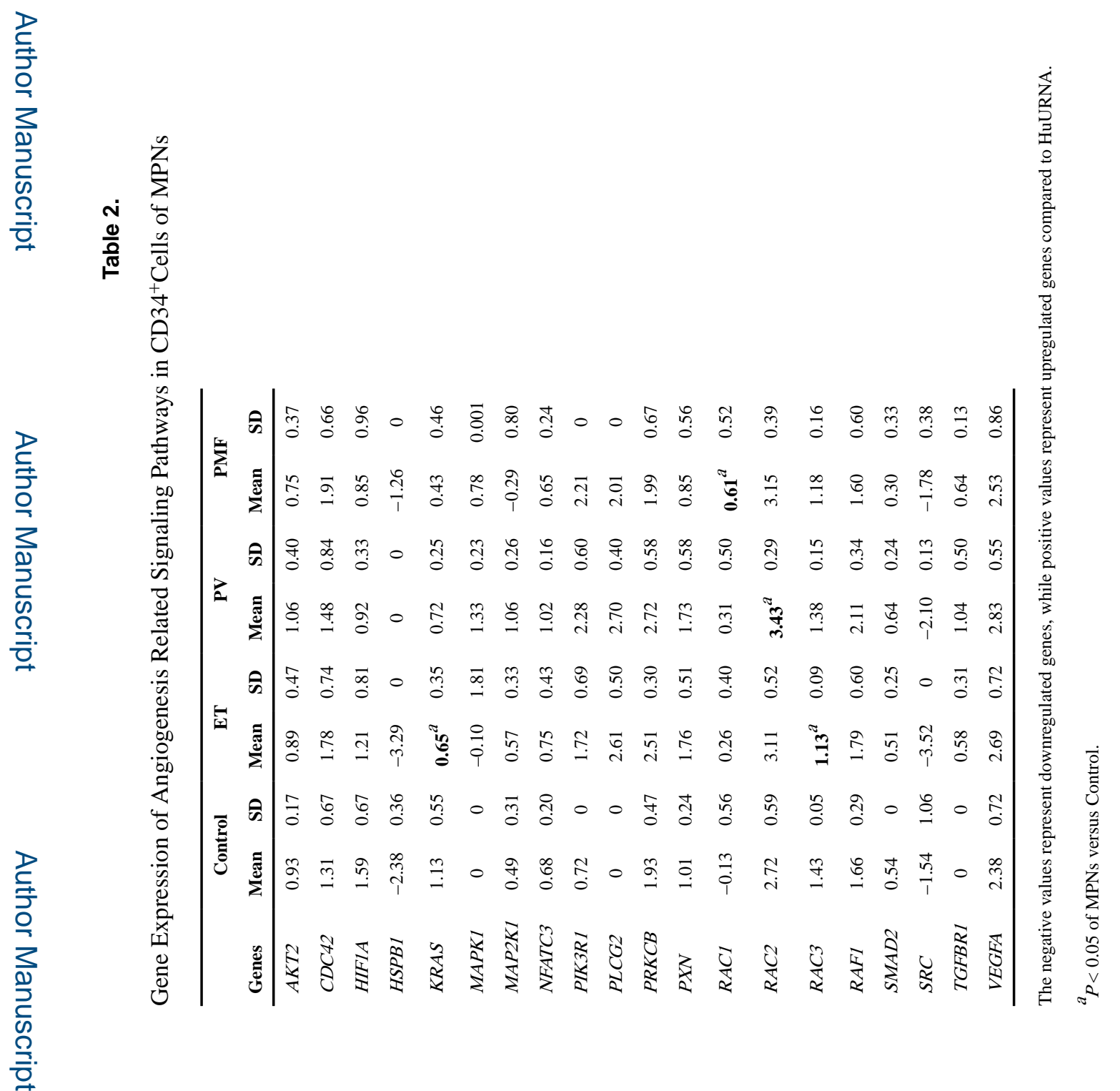

Mol Carcinog. Author manuscript; available in PMC 2020 June 10. 